\title{
A ANÁlISE DE DISCURSO NA PESQUISA ACADÊMICA EM ESTRATÉGIA
}

\section{RESUMO}

Este artigo busca analisar as características epistemológicas e metodológicas da análise de discurso na pesquisa acadêmica no campo da estratégia, oferecendo um olhar introdutório sobre o tema. Especificamente, procura levantar reflexão crítica sobre a estratégia de investigação para problemas que possam ser discursivamente analisados; bem como sobre o planejamento e condução de entrevistas que produzam dados apropriados a esse tipo de análise. As conclusões indicam que a aplicação da análise de discurso é frequentemente difícil, mas, principalmente se os objetivos do trabalho envolvem por um lado a razão crítica, e por outro o interesse em explorar aspectos que circundam decisões estratégicas de forma interpretativa, seus resultados podem trazer compreensão significativa sobre questões culturais e significados compartilhados por executivos e pesquisadores.

Palavras-chave: Análise de Discurso; Estratégia; Metodologia de Pesquisa; Epistemologia.

\section{THE ANALYSIS OF SPEECH IN ACADEMIC RESEARCH STRATEGY}

\begin{abstract}
This article seeks to analyze the epistemological and methodological features of discourse analysis in academic research in the field of strategy, offering an introductory look at the subject. Specifically, it seeks to raise critical reflection on the research strategy for problems that can be analyzed discursively; as well as planning and conducting interviews producing data appropriate to that type of analysis. The findings indicate that the application of discourse analysis is often difficult, but especially if the objectives of the work involved on the one hand the critical reason, and on the other the interest in exploring issues surrounding strategic decisions in an interpretative way, the results can bring significant understanding on cultural issues and meanings shared by executives and researchers.
\end{abstract}

Keywords: Discourse Analysis; Strategy; Research Methodology; Epistemology. 


\section{EL ANÁLISIS DE EXPRESIÓN EN ESTRATEGIA investigación académica}

\section{RESUMEN}

En este artículo se pretende analizar las características epistemológicas y metodológicas del análisis del discurso en la investigación académica en el campo de la estrategia, que ofrece una mirada introductoria en la materia. En concreto, se trata de elevar la reflexión crítica sobre la estrategia de investigación de los problemas que se pueden analizar discursivamente; así como la planificación y la realización de entrevistas productoras de datos adecuado para ese tipo de análisis. Los resultados indican que la aplicación del análisis del discurso es a menudo difícil, pero especialmente si los objetivos del trabajo que implica, por una parte la razón crítica, y por otro, el interés en explorar cuestiones relacionadas con las decisiones estratégicas de una manera interpretativa, los resultados pueden traer la comprensión significativa de factores culturales y significados compartidos por los ejecutivos e investigadores.

Palabras clave: Análisis del Discurso; estrategia; Metodología de la Investigación; Epistemología.

Tania Maria de Oliveira Almeida Gouveia ${ }^{1}$ Eduardo André Teixeira Ayrosa ${ }^{2}$ Isabel Balloussier Cerchiaro ${ }^{3}$ David Macedo Gradvohl ${ }^{4}$

\footnotetext{
${ }^{1}$ Doutora em Administração pela Escola Brasileira de Administração Pública e de Empresas da Fundação Getúlio Vargas - EBAPE/FGV. Professora da Escola Superior de Propaganda e Marketing - ESPM. Brasil. E-mail: almeida.tania@globo.com

${ }^{2}$ Doutor em Administração pela University of London, Inglaterra. Professor da Universidade do Grande Rio UNIGRANRIO. Brasil. E-mail: eayrosa@gmail.com

${ }^{3}$ Doutora em Administração pela Escola Brasileira de Administração Pública e de Empresas da Fundação Getúlio Vargas - EBAPE/FGV. Professora da Universidade Federal Fluminense - UFF. Brasil. E-mail: icerchiaro@uol.com.br 4 Doutorando em Administração pela Universidade do Grande Rio - UNIGRANRIO. Brasil. E-mail: david.gradvohl@gmail.com
} 


\section{AS ANÁLISES DE DISCURSO NA PESQUISA ACADÊMICA EM ESTRATÉGIA}

"We had the experience but missed the meaning. And approach to the meaning restores the experience". (T. S. Eliot, 1941)

O uso de modos de investigação que priorizam a interpretação sobre a explicação causal em estratégia é ainda modesto se considerarmos as possibilidades que seu uso abre. O uso de orientações epistemometodológicas voltadas para a compreensão de subjetividades, e alternativos à abordagem hipotéticopositivista dominante, é já proposto por autores como Silva, Carrieri \& Souza, (2012); Whittington (2006); e Golsorkhi Rouleau, Seidl \& Vaara (2010). Um grupo de formas de investigação interpretativa aborda a realidade como uma descrição textual inclui as chamadas "análises de discurso", e usamos este termo aqui no plural porque existem várias abordagens distintas sob a égide de "análise de discurso". Como será visto ao longo deste trabalho, temos particular interesse naquelas formas de análise que rejeitam a neutralidade do discurso, considerando-o uma forma poderosa de compreender formas de dominação ideológica. Nosso objetivo com este trabalho, portanto, é apresentar estas formas de análise de discurso, e refletir sobre a sua utilidade para investigações em estratégia.

\section{SOBRE PARADIGMAS DE INVESTIGAÇÃO}

A escolha epistemo-metodológica de um projeto está intrinsecamente relacionada à forma como o autor constrói sua trajetória e sua identidade como pesquisador social (SCHWANDT, 2000). O conhecimento envolve um processo de transformação que impacta o próprio pesquisador, individual e coletivamente - por exemplo, quando ele faz escolhas entre diferentes práticas de pesquisa. De acordo com Morgan (1983, p. 405), "essa perspectiva concebe a ciência social como uma atividade que não é apenas epistemológica, mas humana em seu sentido mais amplo." Cada pesquisador aprende ao longo de sua formação escolar e seus anos de trabalho como os seus pares reagem a diferentes paradigmas de investigação. Isso significa dizer que o pesquisador é exposto ao longo dos anos a diversas formas de entender a produção de conhecimento. A pluralidade de paradigmas traz, por um lado, riqueza à área de conhecimento, mas, por outro, exige de seus pesquisadores consciência de que a opção por paradigmas menos populares pode resultar em uma maior dificuldade em ser compreendido plenamente (Burrell \& Morgan, 1979, p. xi).

Ao longo da década de 1960, a área de estratégia passou a apresentar uma orientação epistemológica fortemente positivista e funcionalista. Esta abordagem clássica parte da premissa que os gestores utilizam da racionalidade para alcançar o lucro, visto como o principal objetivo das empresas. $\mathrm{Na}$ década seguinte, outras abordagens começaram a ganhar força, dentre elas, a processualista. Esta abordagem considera que as diversas coalisões dentro das organizações tendem a orientar os objetivos da organização para atender interesses individuais desses pequenos grupos. Nesta visão, os relacionamentos interpessoais se sobrepõem à racionalidade proposta pela abordagem clássica (Silva, Carrieri, \& Souza, 2012; Whittington, 2006). Desta forma, abre-se espaço para abordagens alternativas ao mainstream do campo (Golsorkhi, Rouleau, Seidl, \& Vaara, 2010).

Mas enquanto a maioria dos trabalhos na área de estratégia busca relações causais, gerais e precisas entre dois fenômenos distintos, outros buscam intepretações ou representações do mundo social (Ville $\&$ Mounoud, 2010). De acordo com Burrell \& Morgan (1979, pgs.4 a 7), visões de mundo que opõem objetividade e subjetividade se consubstancializam em debates de ordem ontológica (opondo nominalismo e realismo), epistemológica (opondo positivismo e antipositivismo), metodológica (abordagens ideográficas versus nomotéticas), e acerca da natureza voluntarista versus determinista do homem. A consciência do pesquisador sobre tais visadas opostas e o reconhecimento de sua posição dentro de tais espectros pode abrir campos férteis para o pesquisador disposto a adotar uma perspectiva mais distante do mainstream hipotetico-dedutivo, investigando práticas socialmente construídas em narrativas (Ville \& Mounoud, 2010).

Recentemente, acadêmicos começaram a contemplar aspectos discursivos na formação de estratégia nessas práticas, (i) trazendo narrativas e formas de discursos como atores centrais, (ii) reconhecendo a importância da retórica, e (iii) mostrando as implicações que determinadas concepções de estratégia têm na identidade de alguns atores organizacionais e nas relações de poder (Vaara, 2010).

Nos alinhamos a Vieira e Caldas (2006, p. 59) por afirmarem que, como pesquisadores, não são neutros, pois têm uma posição e percepção do mundo, da teoria e do campo, desenvolvidas a partir de suas condições pessoais e sociais. Assim como estes autores, temos pessoalmente "mais simpatia intelectual e epistemológica" pelas vertentes de pesquisa alternativas ao mainstream funcionalista e à lente positivista que analisa o comportamento social humano a partir de uma perspectiva que prioriza as relações causais e perguntas começadas por "o que" em detrimento de outras começadas por "como". Cabe observar que periódicos relevantes na área de estratégia, elencados por Macmillan (1991), publicam trabalhos que consideram uma abordagem subjetiva, e.g. Knights e Morgan (1991), Barry e Elmes (1997), Paroutis e Heracleous (2013), Hendry (2000), Abdallah 
e Langley (2014), Balogun, Jacobs, Jarzabkowski, Mantere e Vaara (2014), Dameron e Torset (2014), Hardy e Thomas (2014) e Kwon, Clarke e Wodak (2014), sendo esses cinco últimos trabalhos de um número do Journal of Management Studies dedicado ao discurso em estratégia.

Nosso mundo é múltiplo e está em movimento, onde "nem tudo que parece, é". Não acreditamos em verdades absolutas, mas sim que elas são muitas e relativas conforme o contexto. Desta forma, reconhecemos a importância do sujeito, bem como a influência de fatores externos sob $o$ conhecimento humano - como o meio ambiente, o círculo cultural e o espírito da época (Hessen, 2000). Assim, este artigo apresenta e discute, a partir da epistemologia interpretativista, o uso da análise de discurso como método de pesquisa acadêmica em estratégia.

De acordo com Burrell e Morgan (2005), os interpretativistas procuram compreender como o mundo social se manifesta, ou melhor, estão preocupados com a essência do mundo cotidiano, considerando que sua construção acontece em processo contínuo. Schwandt (2000, p. 193) elenca como três principais características da vertente epistemológica interpretativista "(a) a visão de que as ações humanas têm significados (b) o compromisso ético de respeito e fidelidade e (c) o desejo neo-kantiano de enfatizar a contribuição da subjetividade humana ao conhecimento, sem sacrificar o conhecimento objetivo." Tais características se conectam ao pressuposto de que a ação social tem significados intrínsecos compartilhados, o que é uma ideia-chave do pensamento interpretativista.

Nesta busca por significados subjacentes à vida social, o interpretativismo mergulha na subjetividade do ator para compreender suas motivações, crenças e desejos, com a preocupação de entender o mundo social a partir de sua consciência individual. Equivale dizer que a teoria construída por meio do interpretativismo contempla o ponto de vista e as experiências subjetivas dos próprios atores que participam da ação (Schwandt, 2000; Vergara \& Caldas, 2005). Vergara (2008, p. 185) amplia essa explicação ao indicar que a pesquisa de cunho interpretativo integra uma metodologia reflexiva, em que o pesquisador é capaz de "olhar suas próprias perspectivas da perspectiva de outros" - ou seja, envolve a interpretação da interpretação. O conhecimento se dá, nesse caso, a partir da interpretação das representações complexas e subjetivas que constituem a realidade social (Vergara \& Caldas, 2005).

Ao abordarem a construção do conhecimento em estratégia, Laine e Vaara (2010) apontam que o uso de elementos discursivos possibilita a identificação e a análise crítica de diversas questões fundamentais que não são facilmente abordadas pela perspectiva funcionalista. Dentre essas questões, podemos citar as seguintes: (i) como o discurso influencia a formação das relações de poder e da identidade organizacional, (ii) como os discursos constroem a identidade de diversos atores na organização, impedindo ou facilitando sua participação na formação da estratégia e (iii) como o discurso em estratégia faz com que o senso de significação e de realidade dos agentes envolvidos com a estratégia fiquem atrelados à participação desses agentes no discurso e nas práticas da área (Laine \& Vaara, 2010; Vaara, 2010).

Boeira e Vieira (2010, p. 35) argumentam, nesse contexto, que a ciência social "só pode compreender realmente as relações sociais ao incorporar em seus enfoques analíticos o universo interior dos indivíduos - e, sobretudo, a dimensão do sentido que os mesmos conferem a suas ações". Cabe ressaltar, no entanto, que esta ênfase à subjetividade humana não pode ser confundida com renúncia à objetividade do conhecimento. Denzin e Lincoln (2006, p. 197) explicam que "é possível compreender o significado subjetivo da ação (entender as crenças do ator, seus desejos, etc.), porém de uma maneira objetiva", por meio de método corretamente empregado.

Olhando de forma retrospectiva, era imperativo que qualquer executivo de uma organização com fins lucrativos utilizasse ferramentas de planejamento estratégico, indicando uma preponderância da visada trazida pelo paradigma positivista (Barry \& Elmes, 1997; Knights \& Morgan, 1991). Entretanto, as escolas de negócio lutaram para que houvesse uma ressignificação do campo, com o intuito de trazer lentes interpretativistas a acadêmicos e executivos (Barry \& Elmes, 1997; Hendry, 2000).

A visada que temos aqui como objetivo, no entanto, é a de que tomada de decisões estratégicas, por exemplo, não se resume à decisão, mas a todos os seus impactos. Decisões decorrentes da mudança de planejamento estão relacionadas a uma gama de comprometimentos (e.g. investimento em uma nova planta, recrutamento e seleção de pessoal e ajuste do escopo de atuação da empresa) que podem levar meses para se concretizar, e até mesmo nunca serem implementados (Hendry, 2000). Assim, sob a perspectiva interpretativista, podemos analisar os significados destas divergências entre planejamento e execução de estratégias, e entender a intenção do indivíduo ao adotar ou abandonar as decisões tomadas. Tais divergências não apenas por questões utilitárias, mas também para comunicar algo sobre si mesmo, para indicar pertencimento a um grupo, entre muitas outras possibilidades de atribuição de significados (Cyert \& March, 1963; Mintzberg, 1985).

Tendo falando até agora em temas como subjetividade, interpretativismo e a necessidade de compreender o significado das ações, nos aproximamos dos estudos de natureza qualitativa. Trata-se de uma abordagem cujo pressuposto ontológico é o de que a realidade é múltipla e subjetiva e cujas epistemologias que abarca preveem a interação entre o pesquisador e 
os sujeitos ou objetos pesquisados (Goulart \& Carvalho, 2005).

Especificamente sobre as pesquisas em estratégia, estas podem adotar a abordagem tradicional, fundamentada no paradigma funcionalista, ou a de estratégia como prática, fundamentada no paradigma interpretativista. Para a abordagem tradicional, a estratégia é uma propriedade das organizações, portanto, pesquisadores assumem que as organizações têm estratégias de diferenciação, diversificação, jointventure, e que elas têm processos de planejamento estratégico, de decisão e de mudança. Assim, estratégias podem ser vistas como algo desenvolvido por meio de estruturas formais e sistemas, com menor atenção à desordem das relações interpessoais e processos políticos (Golsorkhi et al., 2010; Jarzabkowski, 2005; Johnson, Langley, Melin, \& Whittington, 2007).

Por sua vez, a abordagem de estratégia como prática percebe a estratégia como algo que as pessoas fazem (Golsorkhi et al., 2010; Jarzabkowski, 2005; Johnson et al., 2007), e pesquisadores interessado em estratégia como prática reconhecem a importância (a) de compreender a complexidade dos processos que dão origem à estratégia, e (b) da influência potencial de diversos integrantes da organização, não apenas por meio dos processos formais da organização, mas também por meio de suas atividades cotidianas (Johnson et al., 2007).

Pesquisas baseadas na abordagem tradicional, predominantes no campo da estratégia, se distanciam da realidade dos gestores. Adicionalmente, motivações de ordens econômica, teórica e empírica justificam a necessidade de mudança de abordagem (Johnson et al., 2007). A motivação econômica decorre do ambiente dinâmico e competitivo no qual as empresas trabalham. Neste sentido, a estratégia necessita de mais agilidade, por meio de uma formulação mais flexível e descentralizada. Para que isto seja possível, os estudos em estratégia podem analisar como as ações dos funcionários próximos aos mercados fornecedor e consumidor que contribuem para o processo de desenvolvimento da estratégia (Johnson et al., 2007).

No campo teórico, as pesquisas em estratégia poderiam buscar a relação entre o comportamento do indivíduo e as estratégias da organização. A resourcebased view (RBV), por exemplo, defende que atributos únicos e inimitáveis podem proporcionar vantagens competitivas para a organização, no entanto, as pesquisas relacionadas a esta teoria não fundamentam sua visão às ações dos indivíduos. Por sua vez, as Dynamic Capabilities são fundamentadas na variação de atividades desenvolvidas no nível micro que passam a ter impactos no nível macro, i.e. na capacidade de uma organização se adaptar às mudanças ambientais. Entretanto, os estudos são fundamentados em práticas sistematizadas ou simplificações de comportamento. Por fim, o Institucionalismo sugere que os indivíduos têm um papel chave no processo de institucionalização, pois negociam com o objetivo de compartilhar padrões e comportamentos generalizados. Entretanto, os estudos não apresentam análise detalhada dessas negociações e como elas contribuem para a mudança institucional (Johnson et al., 2007).

Com relação às pesquisas empíricas, essas também necessitam considerar a perspectiva dos indivíduos. Pesquisas em diversificação não conseguiram relacionar a influência da diversificação com a performance da organização. Pesquisas que considerem uma abordagem interpretativista podem auxiliar a entender os motivos e benefícios da decisão em prol da diversificação. O mesmo ocorre com pesquisas sobre estruturas organizacionais, planejamento estratégico, tomadas de decisões e cognição gerencial (Johnson et al., 2007).

$\mathrm{O}$ olhar de estratégia como prática pode ser vista como uma alternativa para as linhas de pesquisa tradicionais, que analisam o efeito da estratégia sobre a performance. Assim, o foco dos estudos se voltaria a uma análise mais profunda e abrangente do que realmente ocorre no planejamento, na execução e em outras atividades que lidam com estratégia (Golsorkhi et al., 2010). Esta abordagem interpretativista surge como um conceito chave para entender questões centrais sobre como agentes e estrutura, bem como ações individuais e institucionais, estão ligadas aos sistemas sociais, às culturas e às organizações (Golsorkhi et al., 2010).

A estratégia como prática é útil para estudar tomada de decisões e trabalho gerencial no nível micro, pois, em geral, as atividades neste nível são ignoradas pelas pesquisas tradicionais no campo, apesar de essas atividades terem consequências significativas para as organizações e seus colaboradores (Johnson et al., 2007). Desta forma, pesquisas podem considerar tanto uma perspectiva da organização sobre estratégia, quanto uma visão estratégica para avaliar os processos da organização. Portanto, a abordagem contribui para a criação de um programa de pesquisa e para a conexão entre a gestão estratégica e pesquisas voltadas à prática (Golsorkhi et al., 2010).

A estratégia como prática é definida como uma ênfase em práticas e processos detalhados que constituem as atividades diárias da vida organizacional e que estão relacionadas a resultados estratégicos (Johnson et al., 2007). Prática é um conceito muito especial que permite pesquisadores se engajarem em um diálogo direto com executivos. Ao se estudar a prática, os pesquisadores podem examinar questões que são relevantes para os executivos que lidam diretamente com estratégia, sejam estrategistas envolvidos com planejamento estratégico, ou outras atividades ligadas à estratégia, ou àqueles que lidam com a estratégia e suas implicações (Golsorkhi et al., 2010).

De acordo com esta visão, as pesquisas devem focar nas práticas que constituem a estratégia, ou seu processo de elaboração, enquanto refletem sobre suas próprias posições, perspectivas e práticas como pesquisadores. Isto inclui a necessidade de embasar, 
aplicar e desenvolver diversas ideias e métodos empíricos (Golsorkhi et al., 2010).

Esta abordagem também contribui de três formas para a formação de uma agenda de pesquisa no campo da estratégia. Inicialmente, o foco na prática possibilita uma oportunidade de examinar o nível micro da atividade social, e de sua construção, em um contexto ou campo, tanto em estudos teóricos, quanto empíricos. Em segundo lugar, a abordagem prática rompe com o individualismo metodológico, enfatizando que as atividades precisam ser compreendidas como permitidas, ou restringidas, pelas práticas dominantes no campo. Por fim, a noção de prática permite que o pesquisador lide com uma das questões fundamentais na análise social contemporânea: como as ações estão relacionadas à estrutura e agência (Golsorkhi et al., 2010).

\section{SOBRE A ANÁLISE DE DISCURSO}

Eu não queria ter de entrar nessa ordem arriscada do discurso; não queria ter de me haver com o que tem de categórico e decisivo; gostaria que fosse ao meu redor como uma transparência calma, profunda, indefinidamente aberta, em que os outros respondessem à minha expectativa, e de onde as verdades se elevassem uma a uma; eu não teria senão de me deixar levar, nela e por ela, como um destroço feliz (Foucault, 2010, p. 7).

Há diferentes níveis de sentido para o que alguém diz, e não apenas o que está explícito. Conforme Koch (2004, p. 23), existe o implícito absoluto "que é aquilo que se introduz por si mesmo no discurso e que o locutor diz sem que o queira e mesmo sem que o saiba" e o implícito relativo, "interno àquilo que o locutor 'quer dizer"'. Todos esses níveis devem ser objeto de interpretação para que o enunciado ganhe sentido. É preciso, portanto, buscar compreender o que está subentendido quando um gestor afirma, por exemplo, que algo foi decidido. Esta decisão se refere à escolha por uma determinada alternativa, que poderá não ser utilizada, ou ao comprometimento esperado pelas pessoas na organização (Hendry, 2000)?

De acordo com Fairclough (2008, p. 21), discurso é "um conceito difícil, principalmente porque há tantas definições conflitantes e sobrepostas, formuladas de várias perspectivas teóricas e disciplinares". Podemos nos referir, por exemplo, ao discurso proferido por alguém, a um discurso vazio, a um discurso de direita ou de esquerda, ao discurso religioso ou a um discurso que remete à mera parolagem - ou seja, discurso é um termo que pode estar relacionado a vários contextos e sentidos.

Como um elemento de linguagem entre interlocutores, discurso remete a algo mais amplo do que a língua em termos formais. Nesse sentido, encontramos em vários autores (Pêcheux, 1993;
Maingueneau, 1997; Brandão, 2006, Fairclough, 2008; Given, 2008; Melo, 2009; Orlandi, 2009; Sarfati, 2010; Charandeau, 2011) a explicação de que o discurso não é apenas um texto, um conjunto de palavras inserido na língua como uma estrutura fixa.

De acordo com Vaara (2010), pesquisas em estratégia vêm recentemente sendo influenciadas por aspectos discursivos. Já para Laine e Vaara (2010), que se voltam especificamente o papel do discurso em estratégia e na formação de estratégias, a abordagem discursiva oferece a possibilidade de entender esses processos por meio da análise do contexto social específico, permitindo entender como as práticas social interferem na elaboração ou implementação de estratégias. Os autores indicam que, pesquisadores vêm colocando a análise de discurso em prática em diversos campos das ciências sociais e humanas. Um exemplo de sua utilização é o trabalho de Vaara e Tienari (2008). Neste trabalho, os autores usam a Análise Crítica de Discurso (ACD) para complementar as conclusões de estudos orientados pela teoria institucional sobre a legitimação de estratégias em empresas multinacionais. $\mathrm{O}$ uso da perspectiva analítica da ACD permite aos autores concluir que alguns interesses específicos são reproduzidos e outros silenciados através de estratégias textuais. O trabalho de Munir e Phillips (2005), por sua vez, faz uso da análise de discurso para compreender o papel de empreendedores institucionais num processo de mudança institucional. Embora Munir e Phillips (2005) dêem destaque à $\mathrm{ACD}$, sua perspectiva é de caráter mais interpretativista que fundamentalmente crítico, e suas conclusões, ao invés de desvelar interesses institucionais ocultos sob estratégias textuais, contribuem para a compreensão das relações entre inovação e teoria institucional. Assim sendo, a escolha da abordagem de análise de discurso depende dos objetivos do pesquisador.

Maingueneau (1997), Brandão (2006), Orlandi (2009) e Charandeau (2011) indicam que o discurso está além da dicotomia saussuriana entre língua e fala, que ele não é neutro, ou um mero instrumento de comunicação, mas um elemento que indica interações, valores, crenças, posições sociais, conjunturas históricas e ideologias. Esses sinais podem ser explícitos ou permanecerem nas entrelinhas, cabendo ao interlocutor os identificar e interpretar.

O conceito de discurso possui nuances de acordo com diferentes visões teóricas que o analisam. De acordo com Melo (2009, p. 3), um ponto em comum entre todas as perspectivas discursivas é o de que o foco não está na língua, mas "no que há por meio dela: relações de poder, institucionalização de identidades sociais, processos, inconsciência ideológica, enfim, diversas manifestações humanas". Essas abordagens de análise a que Melo (2009) se refere são aquelas que Fairclough (2008) define como "abordagens críticas", ou seja, que mostram como o discurso é constituído por ideologias e relações de poder, com efeitos sobre as identidades sociais - que 
lembramos estarem relacionadas, inclusive, a práticas em estratégia.

Ao contrário da análise de conteúdo, a análise de discurso não tem o objetivo de categorizar as falas, encontrar e descrever irregularidades, mas identificar e refletir sobre "dispersão, diferenças e descontinuidade dos planos de onde o sujeito fala" (Godoi, 2010, p. $387)$. Vergara (2008, p. 27) esclarece, no entanto, que a análise de discurso não descarta o conteúdo, mas vai além ao examinar funções, significados e "como o conteúdo é usado para o alcance de determinados efeitos".

De acordo com Melo (2009) e Vergara (2008), há duas principais escolas de análise do discurso: a francesa e a anglo-saxã. Um dos nomes de destaque na análise de discurso francesa (AD) é o de Michel Pêcheux que, a partir do interesse de compreender a ideologia na reprodução social, lançou, em 1969, a obra Análise Automática do Discurso. Ele estudava como as pessoas interagiam pela linguagem e passou a descrever "funções que formas linguísticas realizavam em práticas discursivas específicas; normalmente institucionais e ligadas ao Estado" (Melo, 2009, p. 5). Seu objetivo era analisar a linguagem como um recurso de reprodução do poder hegemônico, partindo da ideia de que o sujeito "não é dono de seu discurso" e de que a língua é "um processo que perpassa diversas esferas da sociedade". Diante da agitação política na França, com o movimento estudantil de 1968, procurava-se, então, analisar elementos históricos, culturais e ideológicos que constituem o discurso (Brandão, 2004). A análise pecheutiana é particularmente indicada para a investigação de casos de incorporação de discursos provenientes de uma esfera de ação social distinta daquela em que o discurso é usado cotidianamente. Em estudos sobra a ação de executivos, esta abordagem é interessante para examinar a forma como discursos provenientes de agentes do mercado penetram na linguagem cotidiana dos estrategistas. Em relações de trabalho, por outro lado, ele ajuda a compreender como discursos do mundo do trabalho penetram nos discursos de uma pessoa em suas relações íntimas fora do mundo do trabalho.

Já numa segunda fase, em meados da década de 1970, a análise de discurso francesa, incorporou a noção de formação discursiva, trazida por Foucault, que se refere àquilo "que determina o que pode/deve ser dito a partir de um dado lugar social que o sujeito ocupa" (Melo, 2009, p. 7). Numa outra etapa, nos anos 1990, passou-se a considerar o interdiscurso, que prevê a heterogeneidade do discurso e a ideia de que um discurso age não sobre não sobre a realidade das coisas, mas sobre o outro.

A corrente anglo-saxã, denominada Análise Crítica do Discurso (ACD), tem origem no livro Language and Control, de 1979, escrito por Fowler, Hodge, Kress e Trew. Seu foco também está no discurso como prática social, mas, particularmente, em uma prática social transformadora. Sob esta perspectiva teórica, a linguagem indica a produção, a manutenção e a mudança de relações de dominação, só sendo possível emancipar-se dessas relações sociais de poder a partir da conscientização sobre elas (Melo, 2009).

O trabalho de Norman Fairclough, produzido no final do século XX, representa importante contribuição no desenvolvimento da noção da linguagem como um elemento de transformação social, indicando que mudanças das práticas sociais pressupõem mudanças também das práticas linguísticas. Fairclough (2008, p. 22) argumenta que o discurso tanto reflete as entidades e relações sociais como as constitui, posicionando as pessoas "de diversas maneiras como sujeitos sociais". Conforme o autor, o discurso contribui para a construção e reconstrução de identidades sociais submetidas a domínios e instituições específicas. Tem, portanto, papel importante na constituição do eu e ajuda a compreender como as sociedades funcionam e como se dão as relações de poder.

Uma leitura comparativa entre a escola francesa de análise do discurso (AD) e a análise crítica do discurso (ACD) indica consonância entre elas no que tange à compreensão do discurso como elemento ideológico e presente tanto na esfera linguística como na social. Conforme Gill (2000, p. 244), as diferentes perspectivas da análise do discurso partilham "uma rejeição da noção realista de que a linguagem é simplesmente um meio neutro de refletir, ou descrever o mundo, e uma convicção da importância central do discurso na vida social". Outros pontos de convergência levam Pinto (2002, p. 24) a mencionar a possibilidade de conciliação teórico-metodológica entre estas vertentes. Conforme o autor, tanto a $\mathrm{AD}$ como a $\mathrm{ACD}$ reconhecem que:

\begin{abstract}
...todo evento de comunicação é ou faz parte de um ritual social cujas convenções devem seguir, (...) que a contextualização passa sempre por mediações, (...) que aquelas marcas [encontradas na superfície textual] são resultado das convenções de codificação exigidas pelo contexto social em que se dá o evento comunicacional; e (...) que o universo dos discursos produzidos numa sociedade se organiza em séries ou redes discursivas.
\end{abstract}

A concepção de sujeito é, contudo, um aspecto de distinção entre essas teorias (Ruchkys \& Araújo, 2001; Melo, 2009). Por um lado, a vertente proposta por Fairclough sugere que o indivíduo, embora tenha uma dimensão passiva, já que é constituído pelo discurso, tem também um papel ativo e de transformação através da linguagem - “ou seja, seria agente no processo de mudança social e cultural através da mudança da práticas discursivas" (Ruchkys \& Araújo, 2001, p. 216). Melo (2009) argumenta, nesse sentido, que, para Fairclough, o indivíduo tanto está subordinado às estruturas como age para modificá-las. Por outro lado, Pêcheux enxerga o indivíduo como elemento da linguagem, mas, dependente de fatores 
externos, está submetido a processos de reprodução de poder. Ele é assujeitado, e não um ator social (Melo, 2009). Ao estudar a noção de sujeito em Pêcheux, Grigoletto (2005, p. 64) indica que "ele tem a ilusão de controle do dizer e, por sua vez, do sentido, sob o efeito de um lugar social, construído pela "norma identificadora' da sociedade para cada indivíduo".

A opção entre a linha francesa e a linha anglosaxã deve-se dar não apenas pela forma pela qual se observa o fenômeno a ser estudado, mas pelo resultado que se projeta para estudo. E note que o resultado aqui não é apenas onde o estudo, em si e dentro de seus limites, chega, mas o impacto que ele pode ter no mundo fora dos limites da própria academia. A principal diferença entre as variedades francesa particularmente a partir da visão pecheutiana e de autores que seguem sua teoria, como Orlandi (2009) e Maingueneau (2013) e Sarfati (2010) - e anglo-saxã (representada por Fairclough) é que a visão crítica francesa não pressupõe uma produção simbólica que vise à transformação social, ponto central na chamada análise crítica de discurso.

\section{SOBRE A COLETA DE DADOS}

Conforme Perakyla e Ruusuvuori (2001, p. 529), a maioria dos estudos qualitativos está baseado nas entrevistas e, "existe uma boa razão para isso". Ao adotar esse recurso de investigação, o pesquisador "alcança áreas da realidade que, de outro modo, permaneceriam inacessíveis, como a subjetividade da experiência e da atitude das pessoas”. Já Gaskell (2000) explica que a entrevista é um método de obtenção de dados qualitativos recomendado quando (1) é preciso explorar o mundo da vida do indivíduo, (2) a pesquisa busca conhecer experiências individuais detalhadas, escolhas e biografias pessoais e (3) o assunto em pauta é complexo ou pode gerar algum embaraço. No entanto, no caso de análises de discurso, é muito comum autores usarem textos já disponíveis, ou seja, dados secundários. Este é, por exemplo, o caso de Vaara e Tienari (2008), que usaram um texto publicado em um jornal diário finlandês, ou Khal e Grodal (2016), que fizeram um levantamento histórico de textos de associações comerciais e reuniões. Empresas geram documentos, deixam vestígios textuais de sua operação como relatórios, emails, memorandos, ou material para uso externo como press releases ou comunicação de marketing, e tais textos são de valor inominável para o analista de discurso. No entanto, o acesso direto a atores nas organizações pode prover dados de valor único, e a melhor forma para ter acesso a tais dados é a entrevista pessoal.

É importante que o pesquisador reconheça que a entrevista pessoal, principalmente a entrevista longa (McCracken, 1988), é usada para produzir dados. Elas diferem das entrevistas estruturadas ou questionários auto-administrados na medida em que não têm como objetivo capturar uma variável ou fato social que se assume como algo que "está lá", que existe independentemente dos sujeitos nele envolvidos. A entrevista longa envolve de profunda pesquisador e pesquisado, e o resultado final existe como fruto direto dessa interação. É um relato pessoal de uma situação no qual residem as formas, objetos e estratégias discursivas que interessam ao analista de discurso. Nesse sentido, os dados são produzidos na interação entre entrevistador e entrevistado. McCracken (1988) vai ainda mais longe ao afirmar que o entrevistador é um instrumento de pesquisa: ele tem voz, corpo, gestual, presença, e integra o evento da entrevista de forma inevitável.

Fisher, Castilhos e Fonseca (2014) organizam seu artigo sobre entrevistas qualitativas em tono de duas abordagens: a fenomenológica e a pósestruturalista. A entrevista que tem como objetivo produzir dados para análise de discurso, principalmente devido à sua postura cética frente à natureza da linguagem e à sua não-neutralidade, tende a se alinhar mais com a abordagem pós-estruturalista.

De acordo com Godoi e Mattos (2010), a entrevista pode assumir a perspectiva de um "evento de intercâmbio dialógico" (Godoi e Mattos, 2010, p. 302), priorizando a dimensão humana na interação entre entrevistado e entrevistador. Acreditamos, assim como estes autores, que os enunciados não estão num vácuo discursivo e que a imprevisibilidade da conversação nos permite "abrir as portas da vida cotidiana ao estranhamento subjetivo e promover o questionamento das manifestações latentes no nível do verbalmente manifesto" (Godoi e Mattos, 2010, p. 316). Encontramos pensamento semelhante em Mishler (1991), que define a entrevista como um discurso que se revela por meio de perguntas e respostas, e cujos significados irão emergir a partir de pressupostos teóricos e analíticos.

Considerando-se, assim como asseveram Belk, Fischer e Kozinets (2013, p. 32), que "uma boa entrevista começa antes que se vá a campo", a etapa de preparação deve ser conduzida com bastante cuidado. Assim, ainda na fase de convite para a concessão da entrevista, os entrevistados (ou sujeitos da pesquisa) devem ler e assinar um protocolo que os informe sobre o processo de entrevista e os garanta direitos de entrevistado. Isso inclui a garantia de anonimato das informações apuradas neste estudo, a autorização para gravação de áudio e/ou vídeo, a reafirmação do caráter voluntário de sua contribuição, a lembrança de que, como informantes, podem se recusar a fornecer informações ou interromper a entrevista nos momentos que acharem conveniente. Devem ser avisados sobre o que o entrevistador espera deles em termos de tempo: que será necessário reservar um período do dia para a entrevista, pois pode não se tratar de uma conversa rápida, e que é difícil prever exatamente quanto tempo a entrevista durará. Há preocupação também em relação ao local de realização de cada entrevista, que deve ser reservado de forma a evitar interrupções e a 
presença de terceiros que possam interferir na conversa ou gerar algum tipo de inibição ao entrevistado.

É importante que o entrevistado fique à vontade, uma vez que a consciência excessiva de si pode interferir na fala - e nas formações discursivas em uso. Para estimular a fala livre dos informantes, o entrevistador deve preocupar-se com o estabelecimento de um bom rapport que, na visão de Vergara (2009, p. 28), "é meio caminho andado" para que o entrevistado se sinta mais confortável e confiante, dando respostas menos racionalizadas e superficiais. McCracken (1988) sugere que entrevistas longas comecem com uma pergunta do tipo grand tour (ver também Belk, Fischer \& Kozinets, 2013), pedindo para que os entrevistados falassem um pouco sobre eles mesmos, sendo estimulados temas como hábitos de lazer, trabalho e família. Busca-se fazer da entrevista uma "conversação aparentemente natural” (Gaskell, 2000, p. 66), procurando explorar determinadas questões sem que a fala do entrevistado seja interrompida e retomando alguns comentários para sua melhor compreensão. Como já citado nesta seção, todas as entrevistas devem ser gravadas em áudio, sendo transcritas em sua íntegra, sem correções ou qualquer comentário adicional por parte do pesquisador.

Considerando, conforme indicam Bauer e Aarts (2000), a construção de um corpus de dados como princípio na coleta de dados qualitativos, a amostragem representativa não se aplica assim como é feito em pesquisa quantitativa. Não há como buscar representatividade se, como pesquisadores qualitativos, o que buscamos são formas discursivas ainda não analisadas ou mapeadas. Mais do que a repetição, interessa aqui a diferença. Nesse contexto, que importa não é a quantidade de entrevistas, mas a coleta de informações diversas e em profundidade até que não se encontre mais variedade, ou seja, até a saturação dos dados (Bauer \& Aarts, 2000; Godoi \& Mattos, 2010).

\section{SOBRE ANÁLISE DE DADOS DISCURSIVOS}

Para a análise dos dados coletados no campo, é preciso identificar parâmetros e critérios para a interpretação, o que, na visão de Gill (2000) e de Godoi (2010) não é tarefa muito simples, já que é mais fácil encontrar discussões conceituais sobre a metodologia do que explicação de como executá-la, praticamente inexistindo um passo a passo de como a análise deve ser feita. "Seria muito agradável se fosse possível oferecer uma receita, ao estilo de manuais de cozinha, que os leitores pudessem acompanhar, metodicamente; mas isso é impossível", argumenta Gill (2000, p. 250).

É importante ressaltar, no entanto, que, embora a análise do discurso não tenha regras sistemáticas para sua condução e para a fixação dos sentidos, bem como implique em arbitrariedade de interpretação (Godoi, 2010), "exige rigor, a fim de produzir um sentido analítico dos textos a partir de sua confusão fragmentada e contraditória" (Gill, 2000, p.
255). Por isso, como pesquisadores precisamos encontrar algum dispositivo de interpretação para os dados coletados. A própria Gill (2010) alinha algumas instruções, a saber: (1) formulação das questões de pesquisa; (2) escolha dos textos a serem analisados; (3) transcrição detalhada do texto; (4) leitura crítica do texto; (5) codificação; (6) exame de regularidades nos dados e criação de hipóteses; (7) teste de fidedignidade e validade, por meio, por exemplo, da análise de casos desviantes e (8) descrição dos resultados.

Orlandi (2009, p. 59) não apresenta regras sistemáticas para interpretação dos dados, mas indica que os dispositivos de interpretação devem buscar "colocar o dito em relação ao não dito, o que o sujeito diz em um lugar com o que é dito em outro lugar, o que dito de um modo com o que é dito de outro, procurando ouvir, naquilo que o sujeito diz, o que ele não diz mas que constitui igualmente os sentidos de suas palavras." A autora menciona como etapas do desenvolvimento da análise dos dados:

- A delimitação do corpus, constituído nesse estudo pelo texto oral como prática discursiva, sendo utilizados princípios teóricos para definir o que faz ou não parte dele. Cabe observar, neste ponto, que a unidade de análise de discurso é o texto, que pode ser uma palavra, uma oração ou um conjunto de frases. Vergara (2008) destaca que deve-se levar em conta também os aspectos paraverbais, como a entonação e as hesitações, bem como os não verbais, como os gestos.

- A de-superficialização do corpus, ou seja, uma análise feita em primeira instância, superficial, avaliando quem diz, o que diz, como diz, a comparação com outros discursos e outras condições de discurso, procurando vestígios sobre as relações de sentidos.

- A análise da discursividade, procurando encontrar processos e sentidos, sem enxergar o texto como produto bruto e acabado. Cabe destacar, neste ponto, que este procedimento caracteriza-se por "um ir-e-vir constante entre teoria, consulta ao corpus e análise." (Orlandi, 2009, p. 67).

Nesta etapa, procura-se, por exemplo, avaliar as possibilidades de formulação do discurso e suas condições de produção, investigar a relação do dizer e não-dizer, identificar interdiscursos e analisar os processos que indicam historicidade da língua, como metáforas e sinonímias. Particularmente sobre a historicidade, não se trata aqui da conexão entre o texto e a história, mas, conforme Orlandi (2009, p. 68), "a historicidade do texto em sua materialidade, (...) o acontecimento do texto como discurso, o trabalho dos sentidos nele". 
A Análise de Discurso na Pesquisa Acadêmica em Estratégia

Embora o texto seja a unidade de análise, ele irá "desaparecer" ao longo desse caminhar analítico, já que o que está em questão é o discurso e, particularmente, o que ele traz de sentido e o que ele indica sobre a constituição dos sujeitos - ou seja, o foco não está no objeto discursivo, mas no processo discursivo.

\section{CONSIDERAÇÕES FINAIS}

O trabalho da estratégia envolve todos os tipos de texto, do mais informal e interno (e.g. conversa nos corredores da empresa) ao mais formal e externo (e.g. matéria em um jornal falando sobre competição, indústrias e mercados). Esses textos estão relacionados à construção, formação de significado e comunicação de uma estratégia, que vão além dos limites da empresa e da atuação de um ator em particular. Entretanto, a estratégia é entendida como algo naturalizado (Balogun et al., 2014), fazendo com que seja necessário repensar a definição de estratégia (Mantere, 2013; Paroutis \& Heracleous 2013). Assim, a investigação de caráter interpretativo, que faz do uso intensivo de dados qualitativos uma forma para acadêmicos observarem fenômenos relativos à formação de estratégias (Balogun et al., 2014).

Além do mais, não se pode restringir a produção acadêmica brasileira de estratégia a reprodução de conhecimento externo (Alcadipani \& Crubellate, 2003). A análise de discurso permite que este processo de "relocalização" se faça de maneira organizada e crítica, uma vez que fornece um quadro referencial que dá suporte à necessidade de relocalização da produção de conhecimento e tentativa de confronto à chamada "colonialidade epistêmica": o processo pelo qual a institucionalização do conhecimento como conhecimento científico permite a integração das elites nativas na ideologia anglo-eurocêntrica dominante da modernidade (Ibarra-Colado, 2006, p. 2). A aplicação de análise de discurso é frequentemente difícil, mas os resultados, principalmente se os objetivos do trabalho envolvem razão crítica, são frequentemente gratificantes.

Considerando-se sua aplicação a temas de estratégia, acreditamos que ela seja de particular serventia aos estudos que têm como objeto a transferência de formas discursivas entre mercados e os indivíduos que têm influência nos processos de elaboração e implementação de estratégias. Estudos com foco em tomadas de decisão (Hendry, 2000), o papel do estrategista (Dameron \& Torset, 2014), formação de sentido de estratégias (Abdallah \& Langley, 2014; Hardy \& Thomas, 2014; Knights \& Morgan, 1991; Kwon et al., 2014; Laine \& Vaara, 2010), estratégias para que os funcionários se identifiquem com a empresa (Vaughn, 1997) e desenvolvimento de uma taxonomia para classificar o conhecimento do campo da estratégia (Paroutis \& Heracleous 2013; Rouleau \& Séguin, 1995) já fizeram uso produtivo da análise de discurso com fins claramente críticos.

\section{REFERÊNCIAS}

Abdallah, C., \& Langley, A. (2014). The Double Edge of Ambiguity in Strategic Planning. Journal of Management Studies, 51(2), 235-264. doi: 10.1111/joms.12002

Abdallah, C., \& Langley, A. (2014). The Double Edge of Ambiguity in Strategic Planning. Journal of Management Studies, 51(2), 235-264. doi: 10.1111/joms.12002

Alcadipani, R., \& Crubellate, J. M. (2003). Cultura organizacional: generalizações improváveis e conceituações imprecisas. Revista de Administração de Empresas, 43, 64-77.

Alcadipani, R., \& Crubellate, J. M. (2003). Cultura organizacional: generalizações improváveis e conceituações imprecisas. Revista de Administração de Empresas, 43, 64-77.

Balogun, J., Jacobs, C., Jarzabkowski, P., Mantere, S., \& Vaara, E. (2014). Placing Strategy Discourse in Context: Sociomateriality, Sensemaking, and Power. Journal of Management Studies, 51(2), 175201.

Balogun, J., Jacobs, C., Jarzabkowski, P., Mantere, S., \& Vaara, E. (2014). Placing Strategy Discourse in Context: Sociomateriality, Sensemaking, and Power. Journal of Management Studies, 51(2), 175201. doi: 10.1111/joms. 12059

Barry, D., \& Elmes, M. (1997). Strategy Retold: Toward A Narrative View Of Strategic Discourse. Academy of Management Review, 22(2), 429-452.

Barry, D., \& Elmes, M. (1997). Strategy Retold: Toward A Narrative View Of Strategic Discourse. Academy of Management Review, 22(2), 429-452. doi: 10.5465/AMR.1997.9707154065

Bauer, M. W., Gaskell, G., \& Allum, N. C. (2000). Qualidade, quantidade e interesses do conhecimento - Evitando confusões. In: Bauer, M. W. \& Gaskell, G. (Eds.), Pesquisa qualitativa com texto, imagem e som. Petrópolis: Vozes.

Bauer, M., \& Aarts, B. (2000). Corpus Construction: A Principle for Qualitative Data Collection. In: Bauer, M. W. \& Gaskell, G. (Eds.), Qualitative researching with text, image, and sound. London : Sage Publication. 
Belk, R. Possessions and the Extended Self. Journal of Consumer Research, v.15, p.139-168, 1988.

Belk, R., Fischer, E., \& Kozinets, R. (2013). Qualitative consumer \& Marketing research. London: Sage.

Boeira, S. L., \& Vieira, P. F. (2010). Estudos organizacionais: dilemas paradigmáticos e abertura interdisciplinar. In: Godoi, C. K., Bandeira-deMello, R., \& Silva, A. B. (Org.), Pesquisa qualitativa em estudos organizacionais: paradigmas, estratégias e métodos. 2. ed. São Paulo: Saraiva.

Brandão, A. (2006). Entre a vida vivida e a vida contada: a história de vida como material primário de investigação sociológica. Revista Configurações, n.3, pp.83-106.

Burell, G., \& Mogan, G. (2005). Sociological Paradigms and Organizational Analysis. Hants: Ashgate,

Burrell, G., \& Morgan, G. (1979). Sociological Paradigms and Organisational Analysis: Elements of the Sociology of Corporate Life. London: Heinemann Educational Books.

Charandeau, P. (2011). Dize-me qual é teu corpus, eu te direi qual é a tua problemática. Revista Diadorim, v. 10, p. 1-23.

Cyert, R. M., \& March, J. G. (1963). Behavioral Theory of the Firm. Englewood Cliffs, New Jersey: Wiley.

Cyert, R. M., \& March, J. G. (1963). Behavioral Theory of the Firm. Englewood Cliffs, New Jersey: Wiley.

Dameron, S., \& Torset, C. (2014). The Discursive Construction of Strategists' Subjectivities: Towards a Paradox Lens on Strategy. Journal of Management Studies, 51(2), 291-319.

Dameron, S., \& Torset, C. (2014). The Discursive Construction of Strategists' Subjectivities: Towards a Paradox Lens on Strategy. Journal of Management Studies, 51(2), 291-319. doi: 10.1111/joms. 12072

Denzin, N. K., \& Lincoln, Y. S. (2006). $O$ planejamento da pesquisa qualitativa: teorias $e$ abordagens. Porto Alegre: Artmed.

Fairclough, N. (2008). Discurso e Mudança Social. Brasília: UnB.
Fischer, E., Castilhos, R. B., e Fonseca, M. J. (2014). Entrevista qualitativa na pesquisa de marketing e do consumidor: abordagens paradigmáticas e orientações. REMark - Revista Brasileira de Marketing, v. 13, n. 4, p. 67-79.

Foucault, M. (2010). A ordem do discurso. Rio de Janeiro: Edições Loyola.

Gaskell, G. (2000). Entrevistas individuais e grupais. In: Bauer, M. W. \& Gaskell, G. (Eds.), Pesquisa Qualitativa com Texto, Imagem e Som. Petrópolis: Vozes.

Gergen, M. M., \& Gergen, K. J. (2000). Qualitative inquiry: Tensions and transformations. In: Denzin, N. K., \& Lincoln, Y. S. (Orgs). Handbook of qualitative research. $2^{\mathrm{a}}$ ed. Thousand Oaks: Sage.

Gil, A. C. (2010). Como elaborar projetos de pesquisa. São Paulo: Atlas.

Gill, R. (2000). Análise de discurso. In: Bauer, M. W. \& Gaskell, G. (Eds.), Pesquisa qualitativa com texto, imagem e som. São Paulo: Vozes.

Given, L.M. (2008). The Sage encyclopedia of qualitative research methods. Thousand Oaks: Sage Publications.

Godoi, C. K. (2010). Perspectivas de análise do discurso nos estudos organizacionais. In: Godoi, C. K., Bandeira-de-Mello, R., \& Silva, A. B. (Org.), Pesquisa qualitativa em estudos organizacionais: paradigmas, estratégias e métodos. São Paulo: Saraiva.

Godoi, C. K., \& Balsini, C. P. V. (2010). Pesquisa qualitativa nos estudos organizacionais brasileiros: uma análise bibliométrica. In: Godoi, C. K., Bandeira-de-Mello, R., \& Silva, A. B. (Org.), Pesquisa qualitativa em estudos organizacionais: paradigmas, estratégias e métodos. São Paulo: Saraiva.

Godoi, C. K., \& Mattos, P. L. C. L.. (2010). Entrevista qualitativa: instrumento de pesquisa e evento dialógico. In: Godoi, C. K., Bandeira-de-Mello, R., \& Silva, A. B. (Org.), Pesquisa Qualitativa em Estudos Organizacionais. São Paulo: Saraiva.

Godoi, C. K., Bandeira-de-Mello, R., \& Silva, A.B. (2010). Pesquisa qualitativa em estudos organizacionais. São Paulo: Saraiva.

Godoy, A. S. (1995). Introdução à pesquisa qualitativa e suas possibilidades. RAE-Revista de Administração de Empresas. São Paulo: v.35, n.2, p. 57-63, abr. 
Golsorkhi, D., Rouleau, L., Seidl, D., \& Vaara, E. (2010). Introduction: What is Strategy as Practice? In D. Golsorkhi, L. Rouleau, D. Seidl \& E. Vaara (Eds.), Cambridge Handbook of Strategy as Practice (pp. 1-20): Cambridge University Press.

Golsorkhi, D., Rouleau, L., Seidl, D., \& Vaara, E. (2010). Introduction: What is Strategy as Practice? In D. Golsorkhi, L. Rouleau, D. Seidl \& E. Vaara (Eds.), Cambridge Handbook of Strategy as Practice (pp. 1-20): Cambridge University Press.

Gontijo, F. (2007). Carioquice ou carioquidade? Ensaio etnográfico das imagens identitárias cariocas. In: Goldenberg, Mirian (Org.). Nu e Vestido: dez antropólogos revelam a cultura do corpo carioca. Rio de Janeiro: Record.

Goulart, S., \& Carvalho, C. (2005). O pesquisador e o design da pesquisa qualitativa em administração. In: Vieira, M. M. F., \& Zouain, D. M. (Orgs.), Pesquisa qualitativa em Administração: Teoria e Prática. Rio de Janeiro: Editora FGV, p. 97-118.

Grigoletto, E. (2005). A Noção de Sujeito em Pêcheux: uma Reflexão acerca do Movimento de Desidentificação. Estudos da Língua(gem), n.1, p. 61-67, jun..

Hardy, C., \& Thomas, R. (2014). Strategy, Discourse and Practice: The Intensification of Power. Journal of Management Studies, 51(2), 320-348.

Hardy, C., \& Thomas, R. (2014). Strategy, Discourse and Practice: The Intensification of Power. Journal of Management Studies, 51(2), 320-348. doi: 10.1111/joms. 12005

Hendry, J. (2000). Strategic Decision Making, Discourse, and Strategy as Social Practice. Journal of Management Studies, 37(7), 955-977.

Hendry, J. (2000). Strategic Decision Making, Discourse, and Strategy as Social Practice. Journal of Management Studies, 37(7), 955-977.

Hessen, J. (2000). Teoria do conhecimento. São Paulo: Martins Fontes.

Hirschman, E. C. (1986). Humanistic inquiry in marketing research: Philosophy, method and criteria. Journal of Marketing Research, v. 23, n; 13, p. 237-249.

Ibarra-Colado, E. (2006). Organization studies and epistemic coloniality in Latin America: Thinking otherness from the margins. Organization, v. 13, n. 4, p. 463-488, Jul.

Jarzabkowski, P. (2005). Strategy as Practice: An Activity Based Approach. Londres: SAGE Publications.
Jarzabkowski, P. (2005). Strategy as Practice: An Activity Based Approach. Londres: SAGE Publications.

Johnson, G., Langley, A., Melin, L., \& Whittington, R. (2007). Introducing the Strategy as Practice Perspective. In G. Johnson, A. Langley, L. Melin \& R. Whittington (Eds.), Strategy as Practice: Research Directions and Resources $\left(1^{\mathrm{a}}\right.$ ed., pp. 129). New York: Cambridge University Press.

Johnson, G., Langley, A., Melin, L., \& Whittington, R. (2007). Introducing the Strategy as Practice Perspective. In G. Johnson, A. Langley, L. Melin \& R. Whittington (Eds.), Strategy as Practice: Research Directions and Resources ( $1^{\mathrm{a}}$ ed., pp. 129). New York: Cambridge University Press.

Kahl, S. J., \& Grodal, S. (2016). Discursive Strategies And Radical Technological Change: Multilevel Discourse Analysis Of The Early Computer (19471958). Strategic Management Journal, 37(1), 149166. doi:10.1002/smj.2453

Knights, D., \& Morgan, G. (1991). Corporate Strategy, Organizations, and Subjectivity: A Critique. Organization Studies, 12(2), 251-273.

Knights, D., \& Morgan, G. (1991). Corporate Strategy, Organizations, and Subjectivity: A Critique. Organization Studies, 12(2), 251-273.

Koch, I. G. V. (2004). Argumentação e linguagem. São Paulo: Cortez.

Kwon, W., Clarke, I., \& Wodak, R. (2014). MicroLevel Discursive Strategies for Constructing Shared Views around Strategic Issues in Team Meetings. Journal of Management Studies, 51(2), 265-290.

Kwon, W., Clarke, I., \& Wodak, R. (2014). MicroLevel Discursive Strategies for Constructing Shared Views around Strategic Issues in Team Meetings. Journal of Management Studies, 51(2), 265-290. doi: 10.1111/joms.12036

Laine, P.-M., \& Vaara, E. (2010). Struggling over subjectivity: a critical discourse analysis of strategic development. In D. Golsorkhi, L. Rouleau, D. Seidl \& E. Vaara (Eds.), Cambridge Handbook of Strategy as Practice (pp. 217-229): Cambridge University Press.

Laine, P.-M., \& Vaara, E. (2010). Struggling over subjectivity: a critical discourse analysis of strategic development. In D. Golsorkhi, L. Rouleau, D. Seidl \& E. Vaara (Eds.), Cambridge Handbook of Strategy as Practice (pp. 217-229): Cambridge University Press. 
Langley, A. (1999). Strategies for Theorizing From Process Data. Academy of Management Review, 24(4), 691-710.

Langley, A. (1999). Strategies for Theorizing From Process Data. Academy of Management Review, 24(4), 691-710. doi: 10.5465/AMR.1999.2553248

Maanen, J. V. (1979). Reclaiming Qualitative methods for organizational research: a preface. Administrative Science Quarterly, v.24, n. 4, dec..

MacMillan, I. C. (1991). The emerging forum for business policy scholars. Strategic Management Journal, 12(2), 161-165.

Macmillan, I. C. (1991). The emerging forum for business policy scholars. Strategic Management Journal, 12(2), 161-165. doi: $10.1002 /$ smj.4250120207

Maingueneau, D. (2013). Análise de textos de comunicação. São Paulo: Cortez.

Maingueneau, D. (1997). Novas tendências em análise do discurso. São Paulo: Pontes.

Mantere, S. (2013). What Is Organizational Strategy? A Language-Based View. Journal of Management Studies, 50(8).

Mantere, S. (2013). What Is Organizational Strategy? A Language-Based View. Journal of Management Studies, 50(8), 1408-1426. doi: 10.1111/joms. 12048

McCracken, Grant. (2008). The Long Interview. Newbury Park, CA: Sage Publications.

Melo, I. F. (2009). Análise do discurso e análise crítica do discurso: desdobramentos e intersecções. Letra Magna, ano 5, n.11.

Miles, M. B. (1979). Qualitative data as an attractive nuisance: the problem of analysis. Administrative Science Quarterly, v.24, n.4, p.590-601.

Minayo, M.C.S.M. (Org.) (1995). Pesquisa social: teoria, método e criatividade. Petrópolis: Vozes.

Mintzberg, H. (1985). The Organization as Political Arena. Journal of Management Studies, 22(2), 133154.

Mintzberg, H. (1985). The Organization as Political Arena. Journal of Management Studies, 22(2), 133154.

Mishler, E.G. (1991). Research Interviewing: Context and Narrative. Cambridge: Harvard University Press.
Morgan, G. (1983). Beyond Method: Strategies for Social Research. California: Sage Publications.

Munir, K. A., \& Phillips, N. (2005). The Birth of the 'Kodak Moment': Institutional Entrepreneurship and the Adoption of New Technologies. Organization Studies (01708406), 26(11), 1665-1687. doi:10.1177/0170840605056395

Orlandi, E. P. (2009). Análise do discurso: princípios e procedimentos. Campinas: Pontes.

Paroutis, S., \& Heracleous , L. (2013). Discourse revisited: Dimensions and employment of firstorder strategy discourse during institutional adoption. Strategic Management Journal, 34(8), 935-956. doi: 10.1002/smj.2052

Paroutis, S., \& Heracleous, L. (2013). Discourse revisited: Dimensions and employment of firstorder strategy discourse during institutional adoption. Strategic Management Journal, 34(8), 935-956.

Pêcheux, M. (1993). Análise automática do discurso. In: GADET, F., \& HAK, T. (orgs). Por uma análise automática do discurso: uma introdução à obra de Michel Pêcheux. São Paulo: Editora Unicamp.

Perakyla, A., \& Ruusuvuori, J. (2011). Analyzing talk and text. In: Denzin, N. K., \& Lincoln, Y. S. (Orgs.) The Sage handbook of qualitative research. 4ed. Thousand Oaks: Sage Publications.

Pinto, M. J. (2002). Comunicação e discurso: introdução à análise de discursos. São Paulo: Hacker Editores.

Pinto, M., \& Lara, J. (2011). As experiências de consumo na perspectiva da teoria da cultura do consumo: identificando possíveis interlocuções e propondo uma agenda de pesquisa. Cadernos EBAPE.BR, Mar, vol.9, no.1, p.37-56.

Rouleau, L., \& Séguin, F. (1995). Strategy and Organization Theories: Common Forms of Discourse. Journal of Management Studies, 32(1), 101-117.

Rouleau, L., \& Séguin, F. (1995). Strategy and Organization Theories: Common Forms of Discourse. Journal of Management Studies, 32(1), 101-117.

Ruchkys, A. A., \& Araújo, M. A. O. M. (2001). Análise do discurso: em busca das (in)congruências entre a vertente francesa e a anglo-saxã. In: Magalhães, C. (Org.). Reflexões sobre a Análise 
Crítica do Discurso. Belo Horizonte: Faculdade de Letras da UFMG.

Santos, H. (2007). O método qualitativo na investigação de sentidos: uma proposta multipolar para estudos organizacionais. In: Vieira, M. M. F., \& Zouain, D. M. (Orgs.), Pesquisa qualitativa em Administração. Teoria e prática. Rio de Janeiro: Editora FGV.

Sarfati, G. E. (2010). Princípios da análise do discurso. São Paulo: Ática.

Schwandt, T. A. (2000). Three epistemological stances for qualitative inquiry: Interpretivism, hermenutics, and social construction. In: Denzin, N. K., \& Lincoln, Y. S. (Orgs.). Handbook of qualitative research, 2 ed. p. 189- 213. Thousand Oaks: Sage Publications.

Silva, A. B., \& Neto, J. R. (2006). Perspectiva multiparadigmática nos estudos organizacionais. In: Godoi, C. K., Bandeira-de-Mello, R., \& Silva, A. B. (Org.), Pesquisa Qualitativa em Estudos Organizacionais. São Paulo: Saraiva.

Silva, A. R. L. d., Carrieri, A. d. P., \& Souza, E. M. d. (2012). A Constructionist Approach for the Study of Strategy as Social Practice. BAR - Brazilian Administration Review, 9(2), 1-18.

Silva, A. R. L., Carrieri, A., \& Souza, E. M. (2012). A Constructionist Approach for the Study of Strategy as Social Practice. BAR - Brazilian Administration Review, 9(2), 1-18.

Thompson, C. J., \& Hirschman, E. C. (1995). Understanding the socialized body: A poststructuralist analysis of consumers' selfconceptions, body images and self-care practices. Journal of Consumer Research, v. 22, n. 2, p. 139153.

Triviños, Augusto N.S. (1987). Introdução à pesquisa em ciências sociais: a pesquisa qualitativa em educação. São Paulo: Atlas.

Vaara, E. (2010). Critical discourse analysis as methodology in Strategy as Practice research. In D. Golsorkhi, L. Rouleau, D. Seidl \& E. Vaara (Eds.), Cambridge Handbook of Strategy as Practice (pp. 217-229): Cambridge University Press.

Vaara, E. (2010). Critical discourse analysis as methodology in Strategy as Practice research. In D. Golsorkhi, L. Rouleau, D. Seidl \& E. Vaara (Eds.), Cambridge Handbook of Strategy as Practice (pp. 217-229): Cambridge University Press.
Vaara, E., \& Tienari, J. (2008). A Discursive Perspective On Legitimation Strategies In Multinational Corporations. Academy of Management Review, 33(4), 985-993. doi:10.5465/AMR.2008.34422019

Vaughn, M. A. (1997). Organizational Identification Strategies and Values in High Technology Industries: A Rhetorical-Organizational Approach to the Analysis of Socialization Processes in Corporate Discourse. Journal of Public Relations Research, 9(2), 119-139.

Vaughn, M. A. (1997). Organizational Identification Strategies and Values in High Technology Industries: A Rhetorical-Organizational Approach to the Analysis of Socialization Processes in Corporate Discourse. Journal of Public Relations Research, 9(2), 119-139.

Vergara, S. C. (2009). Projetos e relatórios de pesquisa em administração. São Paulo: Atlas.

Vergara, S., \& Caldas, M. (2005). Paradigma interpretacionista: a busca da superação do objetivismo funcionalista nos anos 1980 e 1990. RAE-Clássicos, v.45, n.4, 66-72, out/dez.

Vieira, M. M. F. (2006) Por uma boa pesquisa qualitativa. In: Vieira, M. M. F., \& Zouain, D. M. (Orgs.), Pesquisa qualitativa em Administração. Rio de Janeiro: Editora FGV, p. 13-28.

Vieira, M. M. F., \& Caldas, M. P. (2006). Teoria crítica e pós-modernismo: principais alternativas à hegemonia funcionalista. RAE-Revista de Administração de Empresas, v. 46, n. 1, p. 59-70, jan/mar.

Ville, V.-i. d. 1., \& Mounoud, E. (2010). A narrative approach to Strategy as Practice: strategy making from texts and narratives. In D. Golsorkhi, L. Rouleau, D. Seidl \& E. Vaara (Eds.), Cambridge Handbook of Strategy as Practice (pp. 183-197): Cambridge University Press.

Ville, V.-i. d. 1., \& Mounoud, E. (2010). A narrative approach to Strategy as Practice: strategy making from texts and narratives. In D. Golsorkhi, L. Rouleau, D. Seidl \& E. Vaara (Eds.), Cambridge Handbook of Strategy as Practice (pp. 183-197): Cambridge University Press.

Whittington, R. (2006). O que é Estratégia (M. L. G. L. Rosa \& M. M. Leal, Trans.). São Paulo: Thomson Learning. 